\title{
The Effect of Swimming Abilityon the Anxiety Levels of Female College Students
}

\author{
Tajul Arifin Bin Muhamad ${ }^{1}$, Hasti Sattar ${ }^{1}$, Fariba Hossein Abadi ${ }^{1} \&$ Zolkepeli Haron ${ }^{1}$ \\ ${ }^{1}$ Faculty of Education, Universiti Kebangsaan Malaysia, Selangor, Malaysia \\ Correspondence: Tajul Arifin Bin Muhamad, Faculty of Education, Universiti Kebangsaan Malaysia, 43600 \\ UKM Bangi, Selangor, Malaysia. Tel: 60-3-8921-6230/6231. E-mail: tajul.a@ukm.my
}

Received: September 3, 2013

Accepted: September 11, 2013 Online Published: October 29, 2013

doi:10.5539/ass.v9n15p108

URL: http://dx.doi.org/ass.v9n15p108

\begin{abstract}
This study aims to determine changes in the anxiety levels of female college students in relation to their swimming skills. The results of the study were obtained from 141 female college students enrolled at the University of Kebangsaan Malaysia. Breaststroke was used in order to evaluate their swimming skills, while Spielberger's State-Trait Anxiety Inventory (STAI) was used to evaluate their anxiety levels. The analysis and observations confirmed a moderately strong correlation $(\mathrm{r}=-0.407$, sig .000) between the level of anxiety (state anxiety) experienced in the water and swimming skills. The results showed that learning how to swim decreases the anxiety levels of female college students. We suggest that taking up this activity might have benefits for students with high levels of anxiety.
\end{abstract}

Keywords: anxiety, physical exercise, female students, swimming

\section{Introduction}

Physical exercise has become increasingly popular as an effective method for maintaining one's health (Blumenthal et al., 1982). Moreover, regular physical activity has benefits for both physiological and psychological health (Aşçı, 2003; Binsinger et al., 2006). Similarly, a growing number of experimental studies and the existence of several plausible theoretical explanations support the idea that regular exercise yields mental health benefits as well (Aşç1, 2003). Evidence indicate that physical activities also significantly reduce symptoms of anxiety (Asztalos et al., 2012; Readdy \& Ebbeck, 2012). A common feature of these studies is that they all employed aerobic exercises such as jogging, walking, swimming, cycling, aerobic dance, and non-aerobic exercise (weight training) (Boyll, 1985; Long \& Haney, 1988; NOURT \& Beer, 1989; Aş̧̧1, 2003).

Measuring the effectiveness of a sport program does not only require a result-oriented program, but also the athletes' perception and evaluation of the effectiveness of interventions made by coaches and sports psychologists. Perceptions of ability and success of the athletes themselves are important because they are related to the commitment of the athletes to follow the training program as well as their willingness to participate in mental health education and be continuously involved in the program despite the absence of a coach and a psychologist. Integrated principles of biomechanics, physiology, and the nervous system in coordinating the movement must consider psychological factors (Majzub \& Muhammad, 2010).

\section{Anxiety as a Psychological Phenomenon}

The study of anxiety, its antecedents, its relations with other psychological variables, and its consequences has a long history of theoretical and empirical attention within sport psychology (Smith et al., 2006). In fact, anxiety has been one of the most extensively researched topics in sports psychology (Jones, 1995; ANDREW et al., 1999; Woodman \& Hardy, 2003; Jones et al., 2005; Smith et al., 2006; Polman et al., 2007). As a condition characterized by apprehension, tension or uneasiness, anxiety stems from the anticipation of real or imagined danger (Auweele et al., 1999; Liukkonen \& Association, 2007). This relatively normal feeling affects almost everyone at some point in their lifetime. However, if the anxiety becomes excessive and unrealistic, it can interfere with normal functioning (Nieman, 2010).

\section{Anxiety and Learning to Swim}

Nowadays, at the time of growing popularity and availability of various forms of water recreation, swimming has become a desirable and even a necessary skill. Today, swimming is not merely a survival skill to prevent 
drowning, but primarily a sport and a form of relaxation and rehabilitation as well (Ziara, 2005). Therefore, it is recommended that swimming be a main subject for female students. In relation to this, an alarming development can also be observed: the number of female college students who are unwilling to participate in swimming classes, or sometimes openly avoiding them, has been on the increase. For many students, contact with water brings about stress and aversion, and in some cases extreme fear (Barnes et al., 1986).

The current research is significant for three reasons. Primarily, it is likely to provide new information about the effects of swimming on anxiety levels. Carmack et al. (1999); Katula et al. (1999); Binsinger et al. (2006) believe that the result of physical training can significantly reduce anxiety level. Although swimming is generally a popular recreational activity, it does not receive considerable attention in the education system. Therefore, the current study aims to promote greater understanding of the impact of swimming on students' anxiety level.

In addition, the significance of this study depends on determining the effects of swimming on anxiety levels of female students. Helping people generally reduces their anxiety levels, and teaching and helping students learn to swim can also enhance their self-esteem and improve their psychological health. Avramidou et al. (2007) have found a negative linear trend between anxiety and swimming performance as well as a positive linear trend between self-confidence and performance (Avramidou et al., 2007).Thus, learning how to swim may decrease the students' anxiety levels.

Low self-esteem and/or high trait anxiety are potentially linked to risk behaviors, such as abuse of substances (e.g., alcohol, cannabis \& other drugs), risky sexual behavior, suicidal ideation and attempts, dieting, and other extreme weight control methods (Wild et al., 2004; Laure et al., 2005; Binsinger et al., 2006). Young athletes compared with their inactive peers usually show higher self-esteem and lower levels of trait anxiety (Binsinger et al., 2006). To achieve the same objectives, physical activity is often an accessible and helpful instrument (Ekeland et al., 2005). The results of this study will also be significant in motivating physical educators and parents to encourage students to participate in physical activities, especially swimming.

\section{Materials and Methods}

Participants of this study consisted of 141 undergraduate female students from 20 to 30 years old and currently studying at the University of Kebangsaan Malaysia (UKM). They were selected as volunteer participants from different faculties without any knowledge about swimming. They were randomly divided in two groups, namely, control (72 subjects) and experimental (69 subjects) groups. The experimental group participated in a swimming learning course held at the UKM swimming pool from September to November 2012. During the swimming course, the experimental group learned how to swim in the water, dive, and do the breaststroke. Most of the students from the experimental group learned all the materials of the swimming course.

The swimming course was held for 2 hours per session, covering 20 sessions in 10 weeks for that semester. In this research, the sample size suggested 128 subjects (with each group having 64subjects), obtaining a rate of $80 \%$ in the power test and an alpha value of 0.05 , which was calculated using estimation G-power Software version 3.0.10.

\section{Instruments and Administration of Questionnaires}

Progress of the State Trait Anxiety Inventory (STAI) began in the early 1960s with a study on high school and college students (McDowell, 2006). STAI has been found to be a practical tool by Spielberger (Akandere et al., 2002), and is commonly used to measure anxiety in adults (Tilton et al., n. d.; McDowell, 2006). The 20 item STAI is simple, short, and easy to administer (Urological, 2004; Josef \& Krems, 2011). The STAI is also a widely used self-report measure of anxiety (Spielberger et al., 1970).

The STAI questionnaires were completed by all the students of both groups (experimental \& control) on the first day before starting the swimming course and on the last day as part of the post-test procedure. In the current study, state anxiety refers to the experience of anxiety and tension at the moment the questionnaire is completed (i.e., how the subject feels "now"), whereas trait anxiety refers to the general level of anxiety (i.e., how the subject "usually" feels) (Blumenthal et al., 1982; Fountoulakis et al., 2006).

\section{Statistical Analysis}

We performed data analysis using SPSS software. A paired t-test was used for comparing anxiety levels of the participants before and after taking the swimming course. In addition, Pearson correlation coefficient ( $r$ ) tests were conducted in order to investigate the relationship between anxiety and swimming skill among the female students. 
Before discussing the research questions, the summary of information of students such as the mean and standard deviations of age and the semester of both groups (experimental \& control), is shown in Table 1.

Table 1. Age and semester mean and standard deviations of the groups

\begin{tabular}{lll}
\hline Groups & $\mathrm{N}(\dagger)$ & $\begin{array}{l}\text { Age } \\
\text { Mean } \pm \text { SD }\end{array}$ \\
\hline Experimental & $69(49 \dagger)$ & $23.38 \pm 1.81$ \\
Control & $72(51 \dagger)$ & $23.06 \pm 2.03$ \\
Total & $141(100 \dagger)$ & $23.22 \pm 1.92$ \\
\hline
\end{tabular}

In this study, 141 participants were divided into 69 (49\%) subjects in the experimental group and 72 subjects $(51 \%)$ in the control group. The mean age \pm standard deviation (SD) was $23.38 \pm 1.81$ years (range, 20-27 years) for the experimental group and that of the control group was $23.06 \pm 2.03$ years (range, 20-28 years). The participants were studying in various fields, including education, engineering, business, and human sciences.

\section{Results}

The findings mentioned above are very important in reducing the anxiety levels of students by engaging in physical exercise. The mean scores and standard deviations were also calculated for both the experimental and control groups to compare the differences in anxiety levels between the two groups. As shown in Table 2, the means were within the medium range; the experimental group in the post-test $(M=1.50)$ reported lower than the control group $(M=1.95)$. Additionally, the means for the experimental group in the post-test $(M=1.50)$ showed lower than in the pre-test $(M=1.90)$.

The results of the independent-samples t-test, which was conducted to compare the anxiety scores of the experimental and control groups in the pre-test, were shown in Tables 2 and 3, respectively. There was no significant difference in scores for the experimental group $(\mathrm{N}=69, \mathrm{Mean}=1.90, \mathrm{SD}=.44)$ and the control group $(\mathrm{N}=72, \mathrm{Mean}=1.98, \mathrm{SD}=.43 ; \mathrm{t}(139)=-1.21, \mathrm{p}=0.22$, two tailed) (Mean difference $=-.09,95 \% \mathrm{CI}:-.23$ to .05$)$ In addition, as shown in Table 3, the significance level for Levene's test was $0.74(>0.05)$. Thus, the assumption of equal variances was not violated. Moreover, The Sig. (two-tailed) value here was $0.22(>0.05)$. Therefore, the pre-test did not show statistically significant differences between the mean anxiety scores of the experimental and control groups.

The variances for the two groups (experimental \& control) were also different (Tables 2 and 4), owing to the fact that the significance level for Levene's test was $0.14 \geq 0.05$. This means that the assumption of equal variance has not been violated. Furthermore, an independent-sample t-test was conducted to compare the anxiety scores for experimental and control groups in post-test. There was a significant difference between the scores of the experimental group $(\mathrm{N}=69$, Mean $=1.50, \mathrm{SD}=.36)$ and the control group $(\mathrm{N}=72$, Mean=1.95, $\mathrm{SD}=.46 ; \mathrm{t}(139)$ $=-6.48, \mathrm{p}=.000$, two tailed) (Mean difference $=-0.46,95 \% \mathrm{CI}:-0.60$ to -0.32 ). Table 5 shows the significant differences between the two groups of female students (experimental \& control) in terms of anxiety.

\section{Relationship between Anxiety and Swimming Skill}

Swimming skill was graded based on the following four categories as required by FINA rules: 1) the subjects who cannot swim as a control group (72 subjects), 2) subjects who can swim $25 \mathrm{~m}, 3$ ) subjects who can swim $50 \mathrm{~m}$, and 4) subjects who can swim 100m. Moreover, out of the 69 of subjects in the experimental group, 35 swam 25m, 23 swam 50m, and 11 swam 100m.

Pearson correlation coefficient ( $\mathrm{r}$ ) tests were conducted in order to investigate the relationships between anxiety and swimming skill among the female students. The mean total anxiety \pm SD was $1.83 \pm 0.47$. The mean of swimming skill $\pm \mathrm{SD}$ was $1.40 \pm 0.80$ for experimental group. Table 6 shows the descriptive statistics for anxiety and swimming skill. Cohen suggests the following guidelines if $\mathrm{r}=0.10$ to 0.29 , there is a small correlation, $\mathrm{r}=$ 0.30 to 0.49 refers to medium correlation and if $\mathrm{r}=0.50$ to 1.0 , there is a large correlation (Cohen 1988). Table 7 shows a medium correlation between anxiety and swimming skill $(r=-0.407$, sig .000$)$, thereby suggesting a significant negative relationship between anxiety and swimming skill. 
Table 2. Mean \pm SD of anxiety in the pre-test and post-test for each group

\begin{tabular}{llll}
\hline Group & $\mathrm{N}$ & $\begin{array}{l}\text { Pre-test } \\
\text { Mean } \pm \mathrm{SD}\end{array}$ & $\begin{array}{l}\text { Post-test } \\
\text { Mean } \pm \mathrm{SD}\end{array}$ \\
\hline Experimental & 69 & $1.90 \pm .44$ & $1.50 \pm .37$ \\
Control & 72 & $1.99 \pm .43$ & $1.95 \pm .37$ \\
Total & 141 & $1.94 \pm .43$ & $1.73 \pm .48$ \\
\hline
\end{tabular}

Table 3. Independent samples t-test of anxiety in the pre-test

Levene's Test for Equality of Variances t-test for Equality of Means

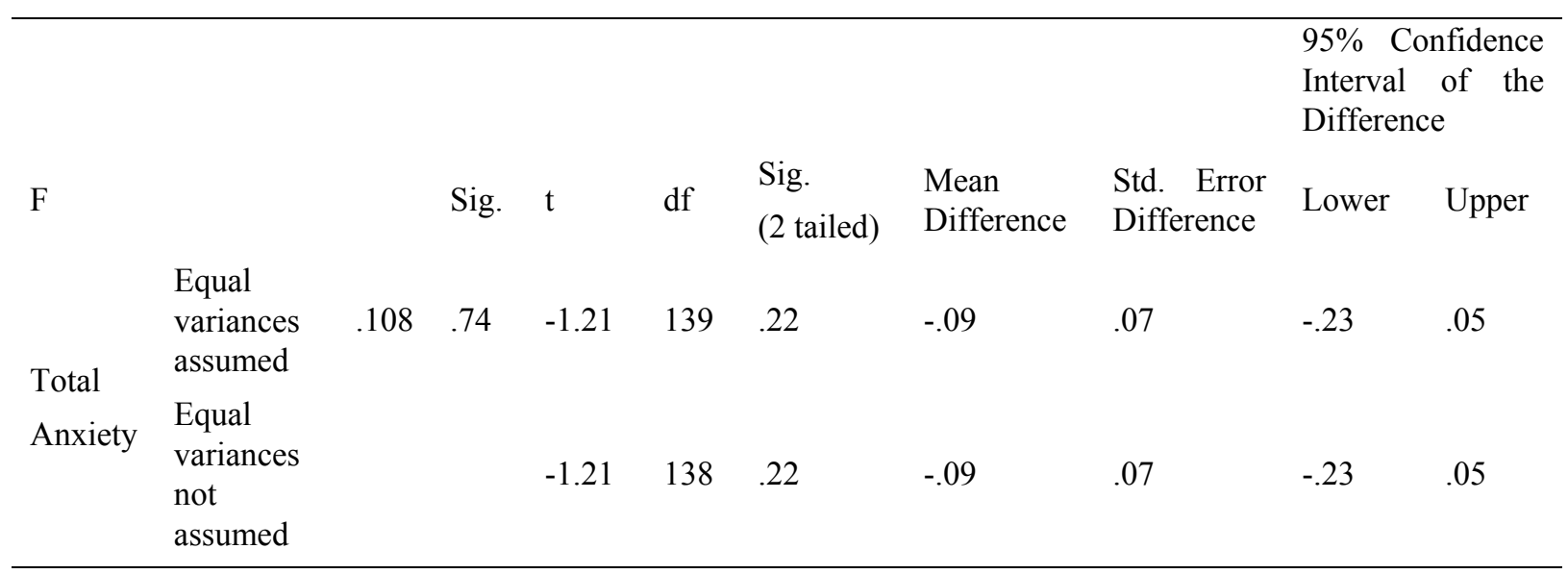

Table 4. Independent samples t-test of anxiety in the post-test

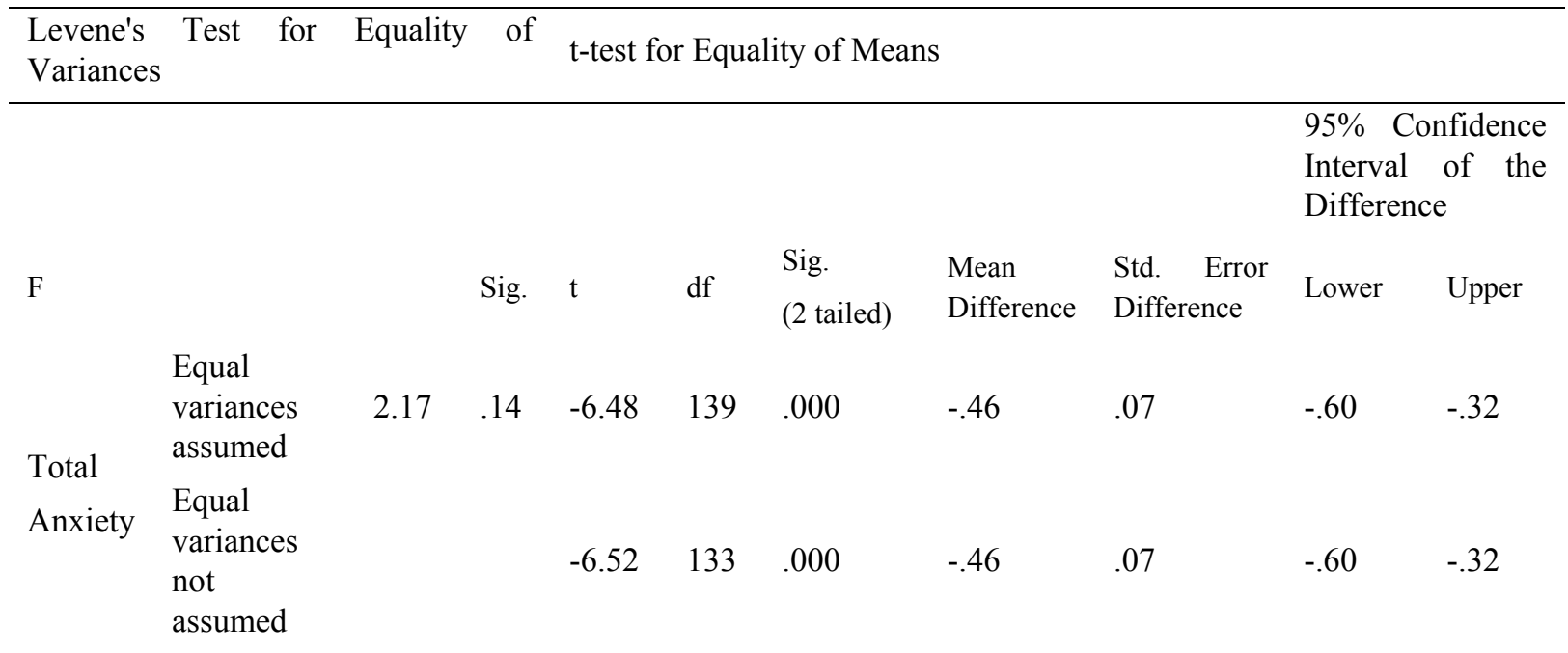

Table 5. The t-test model for anxiety

\begin{tabular}{lll}
\hline & Pre-test & Post-test \\
\hline Experimental \& Control & $\mathrm{NS}$ & $\mathrm{S}$ \\
$\mathrm{N}=141$ & & \\
\hline
\end{tabular}

Note: $\mathrm{NS}=$ no significant, $\mathrm{S}=$ significant 
Table 6. Descriptive statistics

\begin{tabular}{llll}
\hline & $\mathrm{N}$ & Mean & SD \\
\hline Total Anxiety & 141 & 1.83 & .47 \\
Swimming skill & 141 & 1.40 & .80 \\
\hline
\end{tabular}

Table 7. Correlations ${ }^{\mathrm{a}}$

\begin{tabular}{lll}
\hline & Pr & Sig \\
\hline Swimming skill $\quad$ Total Anxiety & $-.407^{* *}$ & .000 \\
\hline **. Correlation is significant at the 0.01 level (2-tailed) & & \\
a. Listwise $\mathrm{N}=141$ & &
\end{tabular}

\section{Discussion}

One of the main causes of anxiety while learning to swim is the fear of drowning. It seems that identification of stimuli that accompany swimming makes it difficult to determine the actual cause of anxiety, especially since the issue is far more complex. The negative emotions, including anxiety, hinder the process of learning how to swim (Ziara, 2005). Thus, when students learn how to swim, they can consequently overcome and reduce their anxiety, indicating that learning how to swim is an activity that reduces anxiety. Similar results can be found in the studies of Sawane and Gupta (2013)andBahrke and Morgan (1978). Nevertheless, Koltyn et al. (2007) and Raglin et al. (1993) also presented similar findings that seem to contradict the abovementioned notion, that is, resistance exercises does not seem to decrease anxiety.

It seems that progress in learning how to swim is based on the systematic repetition of a series of exercises, no different sooner or later, which produces the desired effect (i.e., acquisition of simple swimming skills) that, in turn, signifies reduced anxiety level. Furthermore, it can be assumed that there is some kind of dynamic balance between the level of anxiety in female students in the water and the rate of acquisition of swimming skills. The students' reported aversions and failures may be consequences of disturbing such balance.

The results obtained from the control and experimental groups indicated that their anxiety levels showed the same characteristics at the beginning of the research. The mean of the anxiety scores of control group decreased from 1.99 to 1.95 , while that of the experimental group decreased from 1.90 to 1.50.This supported the notion that swimming had a positive effect on the experimental group; it also supported the assumption that continuous anxiety reduction results from planned physical exercise.

These findings and observations confirm a high correlation between the anxiety level of subjects in the experimental group and their swimming skill. The result also displays a significant impact of swimming on the anxiety level of female college students. Students who showed a higher anxiety level, especially during the first swimming classes, achieved lower results in the swimming skill tests (as confirmed by the qualitative analysis). Nevertheless, despite gradual improvement in swimming skill, the average anxiety level of female students was reduced.

\section{Conclusion}

The results are summarized in this part. Swimming effectively eliminated anxiety among university students and resulted in continued decrease. There was an inverse relationship between physical exercise and anxiety. In addition, the initial anxiety level may have had a decisive impact on further stages of the swimming learning process among the female students. The study of the relationship between the anxiety level and the level of swimming skills reveals a moderately strong negative correlation. Finally, the observed learning progress in the swimming skills of female students also dramatically reduced the average anxiety level.

\section{References}

Akandere, M., Tekin, A., Spor, M. Ü. B. E., Okulu, Y., \& Turkey, A. I. (2002). The effect of physical exercise on anxiety. The Sport Journal, 5(2).

Andrew, M., David, F. S., Peter, C. T., Bartram, D., \& Nesti, M. S. (1999). Confirmatory factor analysis of the competitive state anxiety inventory-2. Journal of Sports Sciences, 17(6), 505-512. http://dx.doi.org/10.1080/026404199365812 
Aşçı, F. H. (2003). The effects of physical fitness training on trait anxiety and physical self-concept of female university students. Psychology of Sport and Exercise, 4(3), 255-264. http://dx.doi.org/10.1016/S1469-0292(02)00009-2

Asztalos, M., Wijndaele, K., Bourdeaudhuij, I., Philippaerts, R., Matton, L., Duvigneaud, N., Thomis, M., Lefevre, J., \& Cardon, G. (2012). Sport participation and stress among women and men. Psychology of Sport and Exercise, 13(4), 466-483. http://dx.doi.org/10.1016/j.psychsport.2012.01.003

Auweele, Y. V., Association, E. S. P., \& Education, E. N. O. S. S. I. H. (1999). Psychology for physical educators. Human Kinetics.

Avramidou, E., Avramidis, S., \& Pollman, R. (2007). Competitive Anxiety in Lifesavers and Swimmers. International Joumal of Aquatic Research and.

Bahrke, M. S., \& Morgan, W. P. (1978). Anxiety reduction following exercise and meditation. Cognitive therapy and research, 2(4), 323-333. http://dx.doi.org/10.1007/BF01172650

Barnes, M. W., Sime, W., Dienstbier, R. A., \& Plake, B. (1986). A test of construct validity of the CSAI-2 questionnaire on male elite college swimmers. International Journal of Sport Psychology.

Binsinger, C., Laure, P., \& Ambard, M. F. (2006). Regular extracurricular sports practice does not prevent moderate or severe variations in self-esteem or trait anxiety in early adolescents. Journal of Sports Science and Medicine, 5, 123-129.

Blumenthal, J. A., Williams, R., Needels, T. L., \& Wallace, A. G. (1982). Psychological changes accompany aerobic exercise in healthy middle-aged adults. Psychosomatic Medicine, 44(6), 529.

Boyll, J. R. (1985). The Effects of Active Exercise versus Passive Electronic Muscle Stimulation on Self-Concept, Anxiety, and Depression.

Carmack, C. L., Moor, C., Boudreaux, E., Amaral-Melendez, M., \& Brantley, P. J. (1999). Aerobic fitness and leisure physical activity as moderators of the stress-illness relation. Annals of Behavioral Medicine, 21(3), 251-257. http://dx.doi.org/10.1007/BF02884842

Cohen, J. (1988). Statistical power analysis for the behavioral sciences. Lawrence Erlbaum.

Ekeland, E., Heian, F., Hagen, K., \& Coren, E. (2005). Can exercise improve self-esteem in children and young people? A systematic review of randomised controlled trials. British Journal of Sports Medicine, 39(11), 792. http://dx.doi.org/10.1136/bjsm.2004.017707

Fountoulakis, K. N., Papadopoulou, M., Kleanthous, S., Papadopoulou, A., Bizeli, V., Nimatoudis, I., Iacovides, A., \& Kaprinis, G. S. (2006). Reliability and psychometric properties of the Greek translation of the State-Trait Anxiety Inventory form Y: preliminary data. Annals of General Psychiatry, 5(2).

Jones, G. (1995). More than just a game: Research developments and issues in competitive anxiety in sport. British journal of psychology, 86(4), 449-478. http://dx.doi.org/10.1111/j.2044-8295.1995.tb02565.x

Jones, M. V., Lane, A. M., Bray, S. R., Uphill, M., \& Catlin, J. (2005). Development and validation of the Sport Emotion Questionnaire. Journal of Sport \& Exercise Psychology.

Josef, F. B. S. F. B., \& Krems, F. (2011). The Fuzziness of Verbal Response Scales. The STAI-T Questionnaire.

Katula, J. A., Blissmer, B. J., \& McAuley, E. (1999). Exercise intensity and self-efficacy effects on anxiety reduction in healthy, older adults. Journal of Behavioral Medicine, 22(3), 233-247. http://dx.doi.org/10.1023/A:1018768423349

Koltyn, K., Raglin, J., O'Connor, P., \& Morgan, W. (2007). Influence of weight training on state anxiety, body awareness and blood pressure. International journal of sports medicine, 16(4), 266-269. http://dx.doi.org/10.1055/s-2007-973003

Laure, P., Binsinger, C., Ambard, M., Girault, S., \& Friser, A. (2005). Can self-esteem and trait anxiety predict drugs use among early adolescents. Psychotropes, 1, 73-90. http://dx.doi.org/10.3917/psyt.111.0073

Liukkonen, J., \& Association, E. S. P. (2007). Psychology for Physical Educators: Student in Focus. Human Kinetics.

Long, B. C., \& Haney, C. J. (1988). Long-term follow-up of stressed working women: A comparison of aerobic exercise and progressive relaxation. Journal of Sport and Exercise Psychology, 10(1988), 461-470. 
Majzub, R., \& Muhammad, T. A. (2010). Goal orientation, attention styles and anxiety of junior golfers in $\begin{array}{llll}\text { Malaysia. Procedia-Social and Behavioral Sciences, } & \text { 9, }\end{array}$ http://dx.doi.org/10.1016/j.sbspro.2010.12.201

McDowell, I. (2006). Measuring health: a guide to rating scales and questionnaires. Oxford University Press, USA.

Nieman, D. C. (2010). Exercise Testing \& Prescription. McGraw-Hill.

NOURT, S., \& Beer, J. (1989). Relations of moderate physical exercise to scores on hostility, aggression, and trait-anxiety. Perceptual and motor skills, 68(3c), 1191-1194. http://dx.doi.org/10.2466/pms.1989.68.3c.1191

Polman, R., Rowcliffe, N., Borkoles, E., \& Levy, A. (2007). Precompetitive state anxiety, objective and subjective performance, and causal attributions in competitive swimmers. Pediatric exercise science, 19(1), 39.

Raglin, J. S., Turner, P. E., \& Eksten, F. (1993). State anxiety and blood pressure following $30 \mathrm{~min}$ of leg ergometry or weight training. Medicine and science in sports and exercise, 25, 1044. http://dx.doi.org/10.1249/00005768-199309000-00012

Readdy, T., \& Ebbeck, V. (2012). Obsessive-compulsive Disorder Symptoms and Correlates in Community Exercisers. Psychology of Sport and Exercise.

Sawane, M. V., \& Gupta, S. S. (2013). Efficacy of Yoga and Swimming in Reducing Anxiety. A Comparative Study.

Smith, R. E., Smoll, F. L., Cumming, S. P., \& Grossbard, J. R. (2006). Measurement of multidimensional sport performance trait anxiety in children and adults: The Sport Anxiety Scale-2. Journal of Sport \& Exercise Psychology, 28, 479-501.

Spielberger, C., Gorsuch, R. L., \& Lushene, R. (1970). The state-trait anxiety inventory: Test manual for form X. Palo Alto: Consulting Psychologists P.

Tilton, S., Spielberger, C. D., Gorsuch, R., Lushene, R., Vagg, P., \& Jacobs, G. (n. d.). Review of the State-Trait Anxiety Inventory (STAI).

Urological, T. A. I. S. A. (2004). Reliability and validity of the Spielberger State-Trait Anxiety Inventory (STAI) among urological patients: a Malaysian study. Med J. Malaysia, 59(2).

Wild, L. G., Flisher, A. J., Bhana, A., \& Lombard, C. (2004). Associations among adolescent risk behaviours and self-esteem in six domains. Journal of Child Psychology and Psychiatry, 45(8), 1454-1467. http://dx.doi.org/10.1111/j.1469-7610.2004.00330.x

Woodman, T., \& Hardy, L. (2003). The relative impact of cognitive anxiety and self-confidence upon sport performance: A meta-analysis. Journal of Sports Sciences, 21(6), 443-457. http://dx.doi.org/10.1080/0264041031000101809

Ziara, W. (2005). Relationships between Progress in Acquisition of Swimming SKILLS and Anxiety Level In Ten-Year-Old Children. HUMAN: 93.

\section{Copyrights}

Copyright for this article is retained by the author(s), with first publication rights granted to the journal.

This is an open-access article distributed under the terms and conditions of the Creative Commons Attribution license (http://creativecommons.org/licenses/by/3.0/). 